\title{
Papeles para la historia de Fluxus y Zaj: entre el documento y la práctica artística
}

\author{
Henar RiviÈRE Ríos \\ Universidad Complutense de Madrid, Dpto. Historia del Arte III (Contemporáneo) \\ \& Freie Universität Berlin, Kunsthistorisches Institut.
}

\begin{abstract}
RESUMEN
Fluxus y Zaj plantean un reto a la historiografía del arte como pioneros del arte de acción. Nacidos a comienzos de los años sesenta, ambos fenómenos de neovanguardia experimental inauguraron este tipo de práctica artística que, poniendo el énfasis en lo eventual y múltiple, rechaza la creación de obras de arte acabadas en sí mismas y destinadas a durar. La dificultad que esto genera para el historiador del arte es abordada en el presente artículo mediante un recorrido que, a través de un trabajo metodológico de aproximación historiográfica, llega a proponer nuevos modos de comprensión e interpretación de tal desafío. Al realizarse de forma comparada entre los dos colectivos, este estudio permite además evidenciar tanto afinidades como significativas diferencias entre ambos, perfilando el carácter y la singularidad de cada uno de ellos.
\end{abstract}

Palabras clave: Fluxus; Zaj; arte de acción; historiografía del arte; fuentes; teoría del arte.

\section{Paper trails for the history of Fluxus and Zaj: between document and art practice}

\begin{abstract}
Fluxus and Zaj issue a challenge to the Historiography of Art as pioneers of Performance Art. Born in the beginning of the sixties, both experimental Neo-Avant-Gardes inaugurated this new kind of artistic practice, which emphasizes eventuality and multiplicity, and thus excludes the creation of concluded, closed, lasting works of art. The present paper deals with the difficulties that such a practice poses to Art Historians. It does so by means of a methodological approach of historiographical reconstruction, to which a critical analysis is applied, allowing for new ways of interpreting and understanding this challenge. Moreover, being carried out as a comparative analysis between both Zaj and Fluxus, this article points out relevant affinities and differences between them, helping outline the character and singularity of each one.
\end{abstract}

Keywords: Fluxus; Zaj; Performance Art; Art Historiography; Sources; Art Theory.

\section{Introducción: ¿salvar distancias?}

Fluxus y Zaj se presentaron con esos nombres por primera vez ante el público a comienzos de los años sesenta. Aunque ambos se mostraron huidizos frente a posibles autodefiniciones, puede identificarse al primero con una red internacional de 
$\operatorname{artistas}^{1}$ y al segundo con un grupo español ${ }^{2}$. Además de ser coetáneos, grupo y red tuvieron importantes afinidades entre sí y colaboraron en numerosas ocasiones. Por ello, parece idóneo estudiarlos de un modo conjunto y comparado que, planteado desde una perspectiva adecuada a ambos, contribuya a definir puntos comunes y matizar divergencias ${ }^{3}$.

La experimentación artística desarrollada por Zaj y Fluxus les convirtió en pioneros del arte de acción. Partiendo de los más recientes desarrollos musicales, y especialmente en conexión con la influencia revulsiva del compositor estadounidense John Cage (1912-1992), desplegaron una propuesta que ponía el énfasis en el proceso de interpretación o performance de las piezas, y renunciaba así al postulado tradicional según el cual el objetivo y resultado de la actividad creativa debía ser la confección de una obra acabada en sí misma. Desvinculándose de tal finalidad, la práctica artística se descubría como un hacer siempre inconcluso y múltiple, un acontecer pasajero y continuo despojado del aura de singularidad propia de la obra de arte y de aquella su presencia física (objetual) que le asegurara una permanencia y un lugar en el tiempo y el espacio históricos. Puede entonces concluirse que el carácter efímero del arte de acción plantea un desafío a la historiografía del arte, una disciplina a la que priva de su "objeto" habitual de estudio para confrontarla con la ausencia de lo sucedido ${ }^{4}$.

El presente artículo quiere ser una aportación metodológica y crítica a esta historia de ausencias. Metodológica, porque ejemplifica posibles modos de acercamiento a la actividad de Fluxus y Zaj a través de las huellas dejadas a su paso, y crítica, porque se fundamenta en la convicción de que esta tarea de salvar distancias sería estéril de no ir acompañada por una reflexión sobre la existencia de las

1 Vid. RIVIÈRE, Henar, "Fluxus: la génesis de una red internacional de artistas o La vanguardia que no tuvo lugar", en FERNÁNDEZ DEL CAMPO, Eva \& RIVIÈRE, Henar (eds.), El arca de Babel. Teoría y práctica artística en el escenario transcultural, Madrid, Abada, en prensa.

2 En la elección de las tres letras que le dieron nombre, tan características de la fonética española, estaba implícita la intención de esta identificación geográfica. BARCE, Ramón, en entrevista inédita con la autora, Madrid, 15 de abril de 2003.

3 Existe una presentación comparada de Zaj y Fluxus realizada por Octavio Zaya; la artista Esther Ferrer los glosó en un ensayo conjunta pero no comparativamente. Entre otros comentarios sobre su relación destacan los de J. Díaz Cuyás. Cf. DÍAZ CUYÁS, José, “Zaj, ¿un cuento chino?”, en SARMIENTO, José Antonio (ed.), Zaj, catálogo de la exposición (Madrid, 1996), Madrid, MNCARS, 1996, pp. 27-28; FERRER, Esther, "Fluxus y Zaj", en Zehar. Boletín de Arteleku, no 28, 1994-1995, pp. 22-25; y ZAYA, Octavio, "Zaj y Fluxus", en Arena Internacional del Arte, n 2, 1989, pp. 68-71.

4 La provocación que "the disappearance act" de Fluxus plantea respecto a los criterios de temporalidad tradicionalmente aplicados a los fenómenos histórico-artísticos es abordada por Ina Blom. En lo referente a Zaj, David Pérez subraya el ataque lanzado por su propuesta contra los "supuestos teóricos en los que se sustentaba el propio sentido" de la historia y la crítica del arte. Cf. BLOM, Ina, The Cut Through Time. A Version of the Dada/Neodada Repetition, Tesis doctoral, University of Oslo, Faculty of Arts, 1999, p. 2; y PÉREZ, David, "El cascabel y el gato: un intento (destinado al fracaso) de contextualización histórica" (1997), en Id., Sin marco: Arte y actitud en Juan Hidalgo, Isidoro Valcárcel Media y Esther Ferrer, Valencia, UPV, 2008, pp. 73-96 p. 85. 
mismas. Así, en un primer apartado presenta y pone a dialogar entre si a diferentes tipologías de documentos remanentes de la actividad de la red y el grupo, localizando los ángulos muertos planteados por cada una de ellas en su función como fuentes para la reconstrucción historiográfica. En el esfuerzo por identificar las causas últimas de estas distancias abiertas entre lo sucedido y su rastro, llega a proponer y defender, en un segundo apartado, la hipótesis de que los artistas de Zaj y Fluxus no solamente fueron conscientes, de un modo u otro, de la existencia de ese intervalo de ausencia, sino que, más aún, intervinieron en o desde él de forma creativa. Las diferentes maneras e intenciones con que lo hicieron resultarán iluminadoras sobre la naturaleza y propuesta de cada uno de estos dos colectivos ${ }^{5}$.

Varios han sido los criterios seguidos para demarcar este estudio. Desde el punto de vista material, el papel constituyó el frágil soporte sobre el que fueron trazándose la mayoría de las huellas del devenir de ambos fenómenos artísticos que, desde su marginalidad respecto a los circuitos oficiales del arte y en función de la consiguiente pobreza de recursos con la que trabajaron, encontraron en él un modo económicamente asequible de dar a conocer y dejar constancia de su existencia. Por ello, la amplia variedad de tipologías, formatos, calidades y diseños con que supieron emitirlo o fomentar su emisión ofrece el corpus documental fundamental para este análisis ${ }^{6}$. En cuanto a la cronología, me ceñiré básicamente a los años

5 Sobre las relaciones de y desde Fluxus con la historiografía del arte, pueden consultarse tres autores: SCHMIDT-BURKHARDT, Astrit, Maciunas'Learning machines. From Art History to a Chronology of Fluxus, catálogo de la exposición (Berlin, 2004) Berlin, Vice Versa, 2003; MILMAN, Estera, "Fluxus History and Trans-History: Competing Strategies for Empowerment”, en FRIEDMAN, Ken (ed.), The Fluxus Reader, London, Academy Editions, 1998, pp. 155-165; MILMAN, Estera, "Historical Precedents, Trans-historical Strategies, and the Myth of Democratization", en Visible Language, vol. 26, n 1-2, 1992, pp. 17-34; y FOSTER, Stephen C., "Historical Design and Social Purpose. A Note on the Relationship of Fluxus to Modernism", en Visible Language, vol. 26, n 1-2, 1992 pp. 35-44. Por el contrario, para el caso de Zaj no conozco ninguna aportación que se concentre en un análisis de su relación con la historiografía del arte enfocado desde la propia actitud del grupo. Cierto es que David Pérez, al comentar el silencio de la crítica y la historia del arte sobre Zaj, menciona entre las causas la propia naturaleza de su actividad (véase: supra, nota 4), sin embargo se concentra sobre todo en juzgar la cuestión desde un punto de vista externo a la misma, a saber, la orientación (política) del discurso de la "vanguardia oficial" española durante el franquismo y postfranquismo. Frente a ello, José Díaz Cuyás recuerda que, si bien la "resistencia a la historia" de Zaj "vendría a ser una consecuencia de las dificultades propias del arte 'moderno' en nuestro país”, también es un fenómeno compartido con "otras manifestaciones artísticas de los sesenta", de modo que puede considerarse como un rasgo "inherente a lo que estas prácticas tienen en común”. Cf. PÉREZ, David (2008), op. cit., pp. 80 y 89-90; Id., "El triángulo (im)posible", en Kalias. Revista de arte, año V, n 10, 1993, pp. 162-169; y DÍAZ CUYÁS, José (1996), op. cit., p. 27.

6 He optado por dejar de un lado o a pie de página las otras dos clases de fuentes que completan las disponibles: las grabaciones sonoras y audiovisuales por una parte, y las referencias orales por otra. En cuanto a las primeras, esta decisión se debe a su escasez y a que, en los casos que fundamentan esta aportación, los artistas no estuvieron involucrados en su producción ni dispusieron posteriormente de las tomas, por lo que no tuvieron ocasión de trabajar con ellas de un modo directo que les permitiera fundir y confundir lo meramente informativo con sus inquietudes artísticas y sociales, como si hicieron sobre el papel. Respecto a las fuentes orales, las entrevistas con los artistas constituyen referencias fundamentales, por lo que se han citado o citarán oportunamente; sin embargo, no serán objeto de estudio al no poder considerarse propiamente rastros dejados por la actividad de Zaj y Fluxus, sino más bien narraciones y recuerdos de sus protagonistas formulados con 
iniciales de andadura de cada colectivo, esto es, a la primera mitad de la década de los sesenta, no sólo por considerar, con Jon Hendricks ${ }^{7}$, que es en los orígenes de un movimiento donde se concentran las peculiaridades que posteriormente se desplegarán en su idiosincrasia y evolución, sino por encontrar que la comparación entre Fluxus y Zaj resulta particularmente fértil en este periodo. Dentro de este marco, he tomado como casos concretos de estudio el gran acontecimiento que dio el disparo de salida a Fluxus, y un tipo de actividad particular que Zaj practicó con frecuencia en sus primeros momentos. El carácter inaugural y estrictamente experimental de estos eventos no solamente no les resta relevancia como ejemplos sobre los que fundamentar unas reflexiones e interpretaciones que trasciendan lo particular, sino que precisamente los convierte, en mi opinión, en ejemplos idóneos para tratar de aproximarse a la esencia de dos fenómenos artísticos que fueron experimentales por definición.

\section{Papeles: fuentes para la reconstrucción histórica.}

El nacimiento "oficial" de la red internacional de artistas tuvo lugar con motivo del Fluxus - Internationale Festspiele neuester Musik (Fluxus - Festival internacional de música novísima) en septiembre de 1962 en la ciudad de Wiesbaden (República Federal alemana o RFA). Consistió en una sucesión de conciertos celebrados en el auditorio del Städtisches Museum a través de los que su organizador George Maciunas (1931-1978) aspiraba a ofrecer una completa muestra de las más novedosas experimentaciones musicales de las que tenía noticia en el momento. A tal fin, preparó un meticuloso programa de las piezas que debían interpretarse en los cuatro fines de semana durante los que estaba previsto que se extendiera el Festival (fig. 1). Este documento constituye, en contra de lo que su extremado detallismo podría sugerir, una fuente confusa para la reconstrucción del evento, cuyo transcurso estuvo marcado por continuos cambios sobre la marcha: tanto los trabajos y su orden de presentación, como los intérpretes o performers, fueron decidiéndose en gran medida de forma espontánea y según circunstancias fortuitas8.

La falta de correspondencia entre lo planificado por Maciunas y su realización no fue un rasgo exclusivo de este Festival. Pocos meses antes, por ejemplo, durante una velada en la Galerie Parnass de Wuppertal que puede considerarse el primer

cierta perspectiva temporal y según los condicionantes de ella derivados, por lo que generan un tipo de problemática que, a pesar de complementarse con la aquí analizada, difiere de ella.

7 Vid. HENDRICKS, Jon, "Fluxus Version A, Wiesbaben 1962", en ROTERS, Eberhard (ed.), Stationen der Moderne. Katalog epochaler Kunstausstellungen in Deutschland 1910-1962 [Kommentarband], Köln, König, 1988, p. 202.

8 Cf. RIVIĖRE, Henar (en prensa), "Fluxus...", op. cit. Nótese la inclusión en el programa de una "Música" de Walter Marchetti y un "Etude" de Juan Hidalgo. Como explicaba éste último, ambos artistas habían sido invitados por Maciunas a enviar piezas. Cf. HIDALGO, Juan, en entrevista (1986) con ZAYA, Octavio (1989), op. cit., p. 70. 


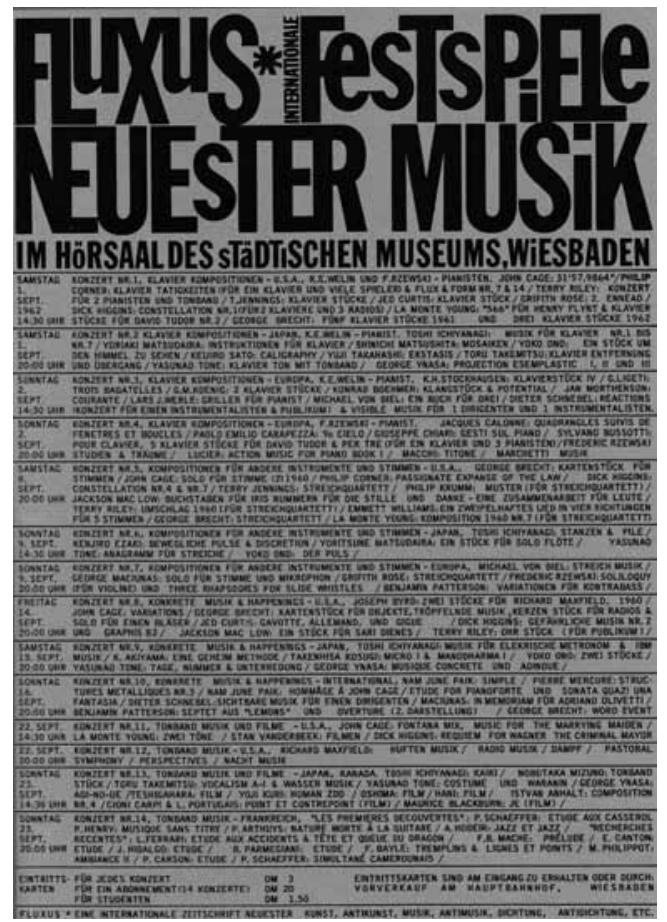

Fig. 1. George Maciunas, Fluxus - Internationale Festspiele neuester Musik, 1962, impresión sobre cartulina, 28 x $20 \mathrm{~cm}$., Berlín (Alemania), cortesía del Archivo Emmett Williams. preestreno de Fluxus, se introdujeron numerosas modificaciones y añadidos al programa de los que queda constancia gracias a unos apuntes escritos a mano en una de las invitaciones 9 . Semejante tipo de correcciones, sin embargo, no siempre están disponibles y en el caso de Wiesbaden las únicas notas sobre el programa conservadas se reducen a la frase que algún anónimo viandante rasgó en el cartel que con él confeccionara Maciunas: "Die Irren sind los", rezaba la inscripción, esto es: "Los locos andan sueltos"10. A cambio, el poeta visual y compositor alemán Ludwig Gosewitz (1936-2007) tuvo la previsión de anotarse las piezas y el orden en que se interpretaron durante los dos fines de semana de septiembre en los que se sumó al público del Museo ${ }^{11}$. Creó con ello una fuente que, en su parcela temporal, goza de una considerable fiabilidad, cotejable además en ciertos casos con los registros fotográficos.

La fotografía adquirió una relevancia documental de primer orden en relación al arte de acción, dando pie a la formación de auténticos especialistas en este ámbito. En lo que a los conciertos de Wiesbaden respecta, junto a las del fotógrafo Hartmut Rekort se encuentran las tomas realizadas por algunos de los propios artistas involucrados, concretamente el citado George Maciunas y el artista visual alemán Wolf Vostell (1932-1998) ${ }^{12}$. No obstante, este material presen-

9 Documento reproducido en BALTZER, Bill \& BIERMANN, Alfons W. (eds.), Treffpunkt Parnass Wuppertal: 1949-1965, Köln, Rheinland Verlag, 1980, p. 192. La información corregida sobre la invitación puede corroborarse con el documento de audio registrado por el Deutscher Rundfunk durante el concierto, hoy en: MoMA New York, Gilbert and Lila Silverman Fluxus Collection Gift. Sobre la consideración de la velada de Wuppertal como el primer preestreno o preludio de Fluxus, cf.: RIVIËRE, Henar (en prensa), "Fluxus...”, op. cit.

10 Fotografía del cartel rasgado en VOSTELL, Wolf (ed.), Décoll/age, nº 3, 1962, s./p.

11 Notas transcritas en GOSEWITZ, Ludwig, "Enschede und Wiesbaden, FLUXUS Autobiografisches", en BLOCK, René (ed.), Wiesbaden-FLUXUS 1962-1982. Eine kleine Geschichte von Fluxus in drei Teilen, catálogo de la exposición (Wiesbaden, 1982), Berlin, Harlekin Art \& Berliner Künstlerprogramm des DAAD, 1983, p. 101.

12 Vid. Archiv Sohm, Staatsgalerie Stuttgart; Archivo Happening Vostell, Museo Vostell Malpartida (Cáceres), y MoMA New York, Gilbert and Lila Silverman Fluxus Collection Gift. Varias de estas fotografías están accesibles en la bibliografía sobre Fluxus y en la Web. 
ta la dificultad de que no siempre es fácil averiguar con qué piezas se corresponden los gestos de los performers. Se hace oportuno entonces recurrir a las partituras o instrucciones de las acciones, y compararlas con las escenas captadas por las cámaras. Como ejemplo emblemático del repertorio de Fluxus puede citarse la Composition 1960 \#10 to Bob Morris del estadounidense La Monte Young (n. 1935) que escuetamente propone trazar una línea recta y seguirla ${ }^{13}$. Esta invitación, tan precisa y abierta a un mismo tiempo, admite ser efectuada de infinitud de maneras distintas. Prueba de ello es la personalísima interpretación que el surcoreano Nam June Paik (1932-2006) le dio en el Festival de Wiesbaden, sumergiendo cabeza y corbata en un cubo de zumo de tomate para pintar con ellas una roja línea recta sobre un papel extendido en el suelo. El hecho de que esta acción haya pasado a la historia con un nombre propio (Zen for Head) independiente del escogido por Young demuestra hasta qué punto entre la propuesta de un compositor y la realización de un intérprete puede mediar una distancia, la cual determinará que entre la indicación de la partitura y el gesto plasmado en un documento fotográfico no exista necesariamente una correspondencia evidente. De este modo, en la apertura de las instrucciones para las acciones se reconoce claramente aquel rechazo arriba comentado de estos artistas a confeccionar obras de arte acabadas en sí mismas ${ }^{14}$.

Otras dos clases de documentos se suman a los papeles para la reconstrucción de los conciertos de Fluxus: las críticas publicadas sobre ellos por la prensa periódica y el intercambio epistolar entre los artistas. Los periódicos y revistas contemporáneos demuestran que la repercusión pública del Festival de Wiesbaden fue excepcional, extendiéndose más allá de las fronteras de la RFA. No obstante, la abundancia de crónicas y artículos de opinión no garantiza una cobertura fidedigna del acontecimiento, ya que la escalada del escándalo, no carente de sensacionalismo, corrió paradójicamente pareja a cierta desvinculación de las recensiones con respecto al propio transcurso de los conciertos. Así, si bien entre los textos se encuentran algunos de considerable precisión, otros se limitan a repetir, copiar e, incluso, tergiversar siempre unas pocas, las mismas referencias a las veladas, insistiendo también a veces en informaciones falsas ${ }^{15}$.

En lo referente a la correspondencia, es destacable aquella mantenida por el prolífico Maciunas con muchos artistas de la red en su rol de impulsor y principal promotor de la misma. Entre la gran cantidad de cartas que escribió pueden encontrarse algunas descripciones de conciertos enviadas a colegas que no habían podido

13 “Draw a straight line and follow it". Cf. YOUNG, La Monte, An Anthology, New York, edición del artista con Jackson Mac Low y diseño de George Maciunas,1963, s./p.

14 Ina Blom proponía replantear la aproximación crítica historiográfica a Fluxus precisamente en función de esta apertura performativa de sus partituras en BLOM, Ina, "The Intermedia-Dynamic", en SCHÜPPENHAUER, Christel (ed.), Fluxus Virus. 1962-1992, catálogo de la exposición (Köln, 1992) Köln, Galerie Schüppenhauer, 1992, pp. 214-220.

15 Una recopilación exhaustiva de recensiones sobre los primeros festivales de Fluxus en Alemania (1962-1963), no estudiadas hasta ahora conjuntamente como corpus crítico, constituye una parte esencial de mi tesis doctoral, en la que trabajo actualmente. 
participar en ellos personalmente. Sin embargo, en los criterios con los que eligió qué era lo que relataba y lo que no, es difícil reconocer una pretensión de rigor semejante a la que ostentara en la preparación del programa para Wiesbaden. Parece que, en ocasiones, se dejó influir por los medios de comunicación, insistiendo, por ejemplo, en las interpretaciones que habían sido incluidas en los seis minutos del reportaje televisado sobre el Festival ${ }^{16}$. Otras veces, puso el énfasis en una subjetiva valoración de las reacciones de los espectadores:

“...quienes más disfrutaron de nuestros conciertos (en Wiesbaden \& París) fueron gente sencilla y no sofisticada como el conserje, trabajadores etc. (y generalmente niños). Y los que más se opusieron fueron todos los pseudointelectuales ... [sic]"17

Por lo demás, los escritos del incansable programador que fue Maciunas abundan en datos acerca de preparativos, algunos exitosos, otros muchos parcial o totalmente fallidos y, por lo tanto, erróneos para la reconstrucción. Con esto, se reabre de nuevo aquel abismo entre lo planificado y lo efectuado con que comenzara este recorrido por los papeles de la red internacional de artistas. Su origen se encuentra en la frecuente imposibilidad de realización, al menos según lo previsto, de los planes que Maciunas formulaba con ambiciosa precisión, y su consecuencia, en una confusión entre "realidad" e "ilusión" que iba a caracterizar la actividad del utópico impulsor de Fluxus. En conclusión, el motivo principal de la dificultad historiográfica para salvar la brecha abierta entre lo sucedido y su huella puede atribuirse a esta confusión "maciunesca", además de a la buscada apertura de ciertas piezas compuestas por los artistas de la red" ${ }^{18}$.

A diferencia de Fluxus, Zaj trabajaba según concisos programas que se cumplían de forma rigurosa durante los conciertos, salvo en los casos en que éstos se vieran interrumpidos por decisiones ajenas a los intérpretes ${ }^{19}$. Desde el inicio de su andadura en 1964, y hasta 1970, el grupo envió por correo postal a sus contactos estos programas en cuidadas invitaciones diseñadas sobre cartones de formatos, calidades y colores variados. Junto a estos documentos de considerable fiabilidad, se dispone además

16 Vid. Carta de G. Maciunas a L. M. Young, 1963, en HENDRICKS, Jon \& PHILLPOT, Clive (eds.), Fluxus. Selections from the Gilbert and Lila Silverman Collection, catálogo de la exposición (New York, 1988), New York, MoMA, 1988, pp. 35-37.

17 En esta aseveración se manifiesta claramente aquello que Estera Milman denomina el "mito democratizador" de Fluxus. Cf. Carta de G. Maciunas a T. Schmit, junio o principios de julio de 1963, reproducida en: HENDRICKS, Jon (ed.), Fluxus etc. /Addenda II: The Gilbert and Lila Silverman Collection, catálogo de la exposición (Pasadena, 1983), Pasadena (Calif.), 1983, p. 161; y MILMAN, Estera (1992), op. cit., pp. 23-24 y 32. Las traducciones del inglés en este artículo son mías.

18 La formulación de una oposición entre "realidad" e "ilusión" en el proyecto de Maciunas se remite a: KELLEIN, Thomas, "I MAKE JOKES! Fluxus aus der Sicht des 'Chairman' George Maciunas", en KELLEIN, Thomas (ed.), Fluxus, catálogo de la exposición (Basel, 1994), Köln, Hansjörg Mayer, 1994, pp. $7-26$.

19 “...un acceso injustificado de pánico por parte de los organizadores del espectáculo hizo suspender el concierto Zaj cuando el grupo se disponía a ejecutar la última obra". MARCO, Tomás, "Concierto tumulto", en SP. Revista de información mundial, año X, nº 289, 1966, p. 46. 
de las partituras de las acciones, las fotografías y las críticas publicadas por la prensa. Es cierto que en el manejo de este material pueden encontrarse motivos de imprecisión semejantes a los comentados a propósito de Fluxus. Sin embargo, el habitual orden del transcurso de las veladas hace más fácilmente identificables las escenas fotografiadas, y se refleja en la claridad de exposición de las referencias de prensa. Entre éstas últimas destaca además la labor realizada por el compositor Tomás Marco (n. 1942) como crítico musical que cubrió, mediante detallados reportajes, gran parte de la actividad desarrollada por el grupo durante sus dos primeros años de andadura ${ }^{20}$. Por último, si bien el intercambio epistolar de Zaj es menos abundante y relevante para la reconstrucción que el de Fluxus ${ }^{21}$, en el caso de la agrupación española existe otro tipo de papeles generados en función del contexto político en que desarrolló su quehacer durante casi una década: las descripciones del contenido de los conciertos preparadas para la censura previa franquista ${ }^{22}$.

La actividad de Zaj sería, por lo tanto, en principio algo más sencilla de reconstruir que la de Fluxus. Sin embargo, en ocasiones adopta un modo muy particular de escabullirse, como evidencia la primera (des)aparición pública realizada en su nombre el 19 de noviembre de 1964. Consistió en un "traslado a pie de tres objetos" por las calles de Madrid realizado por los dos artistas centrales del grupo, Juan Hidalgo (n. 1927) y Walter Marchetti (n. 1931), y su cómplice y colaborador fundacional Ramón Barce (1928-2008). La invitación correspondiente (fig. 2) especifica, con una precisión en este caso irónica, una cantidad de información inusual, pues no solamente incluye la hora y minutos de comienzo del evento, sino también los de su terminación: y es que fue distribuida una vez concluido el suceso. De este modo, no pudo haber espectadores conscientes de serlo, ni tampoco críticos preparados para cubrir el acontecimiento, y la toma de fotografías quedó únicamente a cargo de los artistas o sus acompañantes ${ }^{23}$.

20 En un detallado estudio sobre la recepción crítica de Zaj entre 1964 y 1966, Marco, que se unió al grupo a finales de 1965, constituye la figura central. Cf. RIVIÈRE, Henar, "Especulaciones: Zaj y la crítica española", en Mirando a Clio. El arte español espejo de su historia. Actas del XVIII Congreso Español de Historia del Arte (Santiago de Compostela, 2010), en prensa.

${ }^{21}$ Como ejemplo vid. la traducción de la correspondencia de Zaj con Dick Higgins (1938-1998) entre 1966 y 1973: www.uclm.es/artesonoro/ZAJ/corres.htm (fecha de última consulta: 07.06.2011), parcialmente publicada también en SARMIENTO, José Antonio (ed.), Escrituras en libertad. Poesía experimental española e hispanoamericana del siglo XX, catálogo de la exposición (Madrid, 2009), Madrid, Instituto Cervantes, 2009, pp. 276-280.

22 Vid. documento transcrito en SARMIENTO, José Antonio (ed.) (1996), op. cit., p. 67.

23 La única referencia en la prensa contemporánea es de Marco y no alude al transcurso del suceso sino al texto de la invitación al mismo. Respecto al registro fotográfico, las dos tomas conocidas son de Elena Martín, mujer de Ramón Barce. Cf. MARCO, Tomás, "Música de acción", en SP. Revista de información mundial, año VIII, n 248, 1964, p. 65; para las reproducciones de las fotografías vid. VVAA., Zaj. Colección Archivo Conz, catálogo de la exposición (Madrid, 2009), Madrid, CBA, 2009, p. 45, y SARMIENTO, José Antonio (ed.) (1996), op. cit., p. 15. 
Éste no fue el único ejemplo en el que Zaj desafió los conceptos al uso de "concierto" y "público" mediante un transitar urbano o rural. En la primavera de 1965, los tres fundadores del grupo interpretaron, junto a varios colaboradores, piezas propias y de John Cage por plazas, glorietas, calles y bares de Madrid, mientras que a finales del mismo año, Hidalgo y Marchetti junto a Marco, entre otros, realizaron un "viaje musical" al pueblo de Almorox. A pesar de que en estos casos los cartones de invitación si fueron enviados con antelación, el hecho de abandonar las salas habitualmente consagradas a las presentaciones musicales y salir a espacios públicos por antonomasia, paradójicamente suponía convertir el hacer artístico en una suerte de práctica privada que, abriéndose al bullicio de lo cotidiano, tendía a disolverse en él.

La programación del madrileño

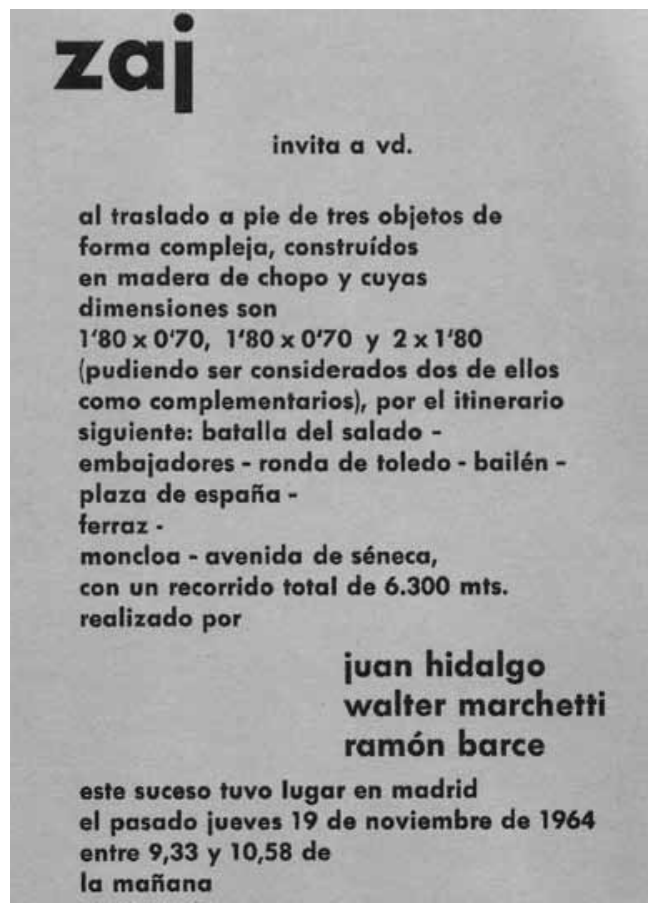

Fig. 2. Zaj, Zaj invita a vd., 1964, impresión sobre cartón, 12 x $16 \mathrm{~cm}$. transitar estaba prevista de antemano pero "el orden de interpretación de las obras" sería "fijado media hora antes del concierto"; por su parte, el anuncio del Viaje a Almorox comunicaba que las piezas serían escogidas sobre la marcha, según el tiempo, el humor o el número de intérpretes $^{24}$. Se puede concluir así que, si en lo concerniente a Fluxus la distancia entre el acontecimiento y el documento se originó de forma involuntaria, en la medida en que la causara lo ilusorio de la planificación maciunesca, por su parte Zaj activó este abismo muy conscientemente al emitir papeles informativos que ofrecen a su lector, contemporáneo o futuro, bien una suerte de juego temporal del escondite (en el Traslado inaugural), bien una previsión de azar (en los otros dos ejemplos). ¿Componía acaso Zaj estas invitaciones de un modo parangonable al que subyace a ciertas partituras de Fluxus ${ }^{25}$ ?

\footnotetext{
${ }^{24}$ Cf. respectivamente: ZAJ, Concierto zaj, mayo de 1965; y ZAJ, Festival Zaj 1, nov.-dic. de 1965.

${ }_{25}$ También entre las partituras de Zaj puede encontrarse una apertura compositiva afín a la comentada a propósito de Fluxus. Como ejemplo emblemático considérese el Mandala de Walter Marchetti, quien se limita a comunicar que "el compositor no está en condiciones de dar al intérprete o intérpretes ninguna indicación acerca de la realización de este mandala". Para más información acerca de posibles interpretaciones diferentes de esta pieza, cf. SARMIENTO, José Antonio (ed.) (1996), op. cit., pp. 51, 60, 62, 80, 86 y 106, y DÍAZ CUYÁS, José (ed.), Encuentros de Pamplona 1972: fin de fiesta del arte experimental, Madrid, MNCARS, 2009, p. 204.
} 
Una vez concluído el Viaje a Almorox, los artistas fijaron por escrito el programa ejecutado ${ }^{26}$, dando lugar a una fuente historiográfica en que se genera una dinámica contradictoria inversa a la de aquel programa preparado por Maciunas para Wiesbaden: mientras el exceso de celo y exactitud organizativa de este último disminuía su fiabilidad informativa, la toma en consideración de lo impredecible en el documento de Zaj la aumenta.

\section{Traspapeles: usos y transformaciones del documento}

Como ha podido apreciarse, la emisión de gran parte de los materiales comentados corrió a cargo de los propios artistas de Fluxus y Zaj que, además de escribir partituras, editar programas, invitaciones y carteles, tomar fotografias, intercambiar correspondencia e informar a la censura, se preocuparon de fomentar, cada uno según sus propios recursos y criterios, una repercusión en los medios de comunicación ${ }^{27}$.

En el caso de los artistas de la red, resulta significativo el hecho de que, lejos de sentirse incómodos por la mala prensa que recibieron, contaran entre ellos con quienes recopilaran las recensiones para utilizarlas en ediciones a su cargo. Maciunas las empleó con fines propagandísticos, diseñando el folleto Ekstra Bladet (Fluxus Newspaper Roll) (1963) con recortes de periódico referentes a varios festivales de Fluxus en Europa, para atraer al público neoyorquino ${ }^{28}$. Por su parte, Wolf Vostell había reproducido también varias crónicas en el tercer número de su revista Décollage, publicado en diciembre de 1962 con documentación de las diversas tipologías que se han analizado en este artículo, junto a ensayos y poemas visuales de diferentes artistas ${ }^{29}$.

Esta actividad de Vostell no fue, sin embargo, bien acogida por Maciunas, que entre las páginas de Décollage reconoció aportaciones para cuya publicación se reservaba la primicia. Así las cosas, el 1 de enero de 1963 distribuyó entre una veintena de artistas la Fluxus News Letter No. 5 por la que les comunicaba su decisión de convertirse en editor vitalicio de las obras completas de cada uno de ellos, a cambio de ostentar la exclusividad de sus derechos de reproducción "para proteger a los autores de la copia e

${ }^{26}$ Cf. ZAJ, Festival Zaj 1 - Viaje a Almorox, diciembre de 1965.

27 A petición de Maciunas, el poeta Emmett Williams (1925-2007) "infiltró" en la edición europea de la revista de las fuerzas armadas norteamericanas The Stars and Stripes, en la que trabajaba, una entrevista ficticia con el compositor Benjamin Patterson (n. 1934), publicada dos días antes del primer concierto del Festival de Wiesbaden. En el caso de Zaj, destacan la labor de Ramón Barce como teórico musical (1964-1965) y la ya citada de Tomás Marco como crítico (1964-1966). Cf. WILLIAMS, Emmett, "Way Way Way Out", en The Stars and Stripes, 30 de agosto de1962, reproducido en: BLOCK, René (ed.) (1983), op. cit., pp. 81-83; y RIVIËRE, Henar (en prensa), "Especulaciones..." op. cit.

${ }_{28}$ Reproducido en HENDRICKS, Jon (ed.), Fluxus Etc. The Gilbert and Lila Silverman Fluxus Collection, catálogo de la exposición (Bloomfield Hills, 1981), Bloomfield Hills (Mich.), 1981, pp. 230-231.

${ }_{29}$ VOSTELL, Wolf (1962), op. cit., s./p. 
interpretación no autorizada" ${ }^{30}$. Tal pretensión monopolizadora (que, salvo en contadas excepciones, fue ignorada o mal acogida por los concernidos), suponía un intento de consolidar su propia iniciativa editorial: un ambicioso proyecto de afán enciclopédico que, si bien no había logrado aún materializarse en ninguna publicación concreta, constituía la razón de ser originaria de Fluxus según la concepción de Maciunas. De hecho, la serie de conciertos y festivales europeos que arrancaron con aquel primer preestreno de la Galerie Parnass de Wuppertal, había sido esbozada por él como un medio de promoción y recaudación de fondos para la edición de un ciclo internacional de revistas antológicas de arte experimental, interdisciplinario y de acción, titulada Fluxus. Como estrategia financiera, su plan cosechó un rotundo fracaso pero, a cambio, impulsó el nacimiento del fenómeno artístico que a partir del Festival de Wiesbaden pasaría a identificarse con el nombre escogido para su proyecto editorial ${ }^{31}$.

Tanto en Wuppertal como en Wiesbaden, Maciunas distribuyó sendas versiones del folleto Fluxus (Brochure Prospectus for Fluxus Yearboxes), donde informaba acerca del comité editorial y del contenido de los siete primeros números previstos de su antología (fig. 3). Más marcadamente que en el caso del programa del Festival (fig. 1), la correspondencia entre la detalladísima declaración de intenciones aquí ofrecida y su realización efectiva fue escasa ${ }^{32}$. De tal suerte que lo que estos documentos ilustran es,

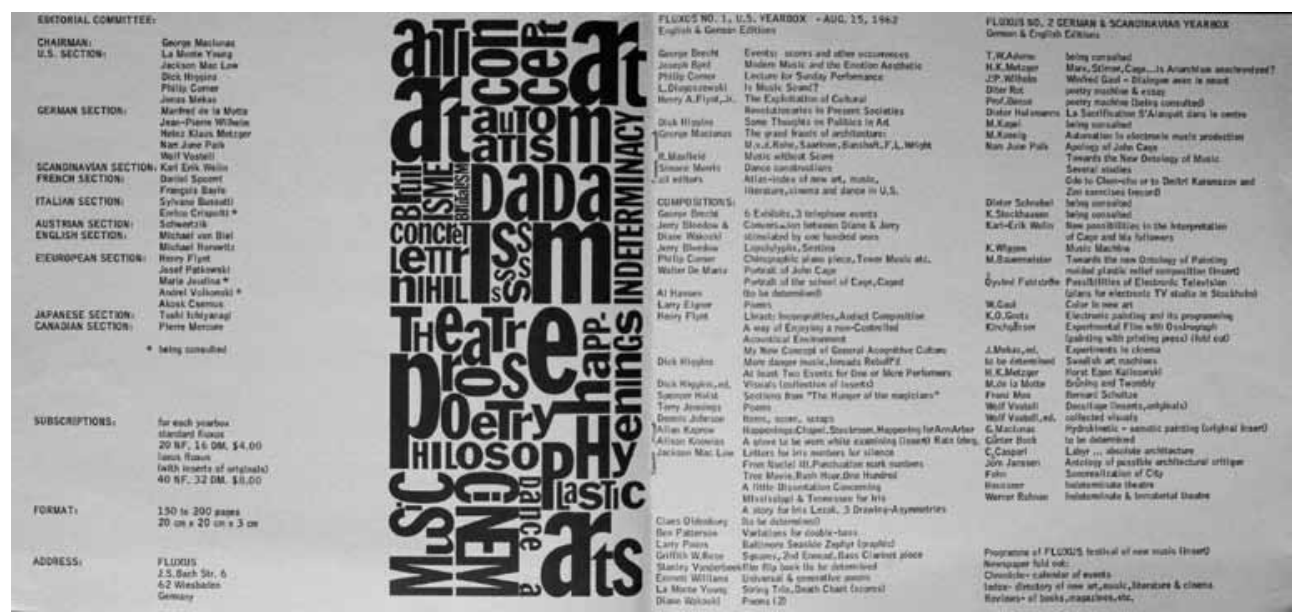

Fig. 3. George Maciunas, dos hojas del Fluxus (Brochure Prospectus for Fluxus Yearboxes), 1962, offset sobre papel de prensa (reproducción facsímil), 20 x 21 cm., Berlín (Alemania), Kunstbibliothek, 8199712210.

30 Reproducida en HENDRICKS, Jon (ed.), Fluxus etc. /Addenda I: The Gilbert and Lila Silverman Collection, catálogo de la exposición (Purchase, 1983), New York, Ink \&., 1983, p. 155.

31 Para más información vid. RIVIÈRE, Henar, (en prensa), "Fluxus...", op. cit. Sobre la debacle económica de los conciertos europeos, cf. KELLEIN, Thomas (2007), op. cit., pp. 67 y 75-79.

32 Sobre las ediciones Fluxus cf. SMITH, Owen F., "Developing a Fluxable Forum: Early Performance and Publishing", en FRIEDMAN, Ken (ed.) (1998), op. cit., pp. 12-19; y HENDRICKS, Jon, "Uncovering Fluxus-Recovering Fluxus", en KELLEIN, Thomas (ed.) (1994), op. cit. (edición inglesa: Thames \& Hudson, 1995), pp. 121-123. 
más que nada, la voluntad universalista con que Maciunas trató de abarcar y coordinar bajo una misma bandera la más novedosa experimentación artística de su época. Incansable recopilador de datos, listaba nombres de artistas y piezas, contando con ellos aunque no conociera a los primeros ni dispusiera de los segundos. Esta práctica acumulativa, que fue frecuente también en su actividad como diseñador y artista ${ }^{33}$, constituía el paso previo a un proceso de clasificación que, por ejemplo, en el caso del programa y el folleto vistos (figs. 1 y 3 ) siguió un principio geográfico. Mucho más elaborados fueron los criterios con que Maciunas fijó los ejes de coordenadas de diagramas como el Fluxus (Its Historical Development and Relationship to Avant-garde Movemets) (c. 1966) (fig. 4), donde los nombres vinculados a Fluxus y actividades afines se agrupan cronológicamente (eje horizontal) y en función de adscripciones estético-teóricas

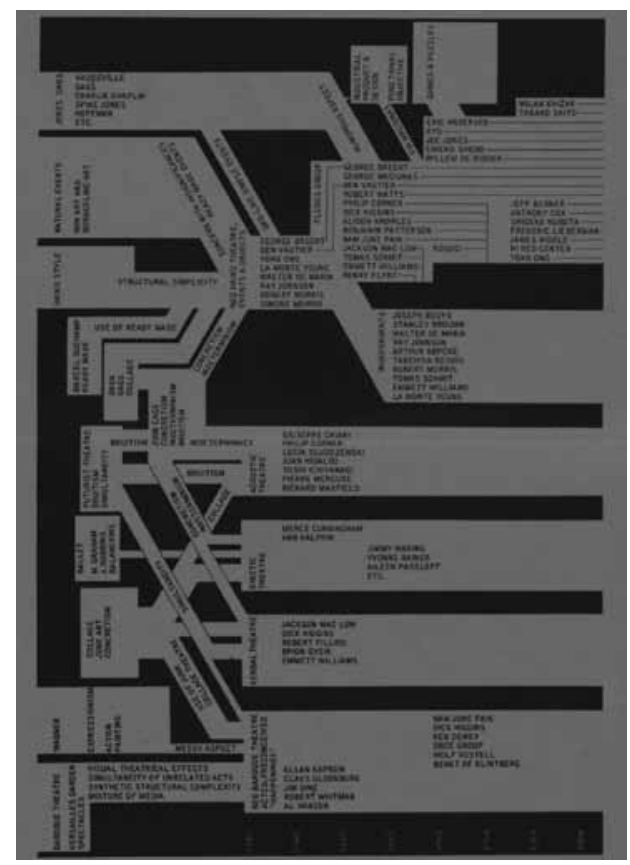

Fig. 4. George Maciunas, Fluxus (Its Historical Development and Relationship to Avant-garde Movements), ca. 1966, offset sobre papel, detalle, Berlín (Alemania), Kunstbibliothek, NB Sohm 437. originadas sobre precedentes inmediatos y remotos (eje vertical).

Con que (¡al fin lo vemos!), con la elaboración de sus listados de nombres, apellidos y títulos de composiciones, para programas de festivales y series editoriales, Maciunas aspiraba a crear historia. Y el carácter apriorístico de su afán no sólo puede reconocerse en el hecho de que ya desde finales de 1961 estuviera aplicando a su proyecto promocional este tipo de ordenación histórica diagramática que respondía a su deseo de reconfigurar el conocimiento y sobre la que seguiría trabajando toda su vida ${ }^{34}$, sino que queda nítidamente puesto en evidencia por los desajustes, tantas veces comentados en estas páginas, entre sus pretensiones y los eventos por ellas desencadenados. Se puede así concluir que la involuntaria distancia que media entre lo sucedido y los correspondientes documentos generados por Maciunas responde a su voluntad de escribir la historia de Fluxus sobre la marcha o, incluso, por anticipado.

33 Cf. MOORE, Barbara, "George Maciunas: A Finger in Fluxus”, en Artforum, vol. XXI, n 2, October 1982, pp. 40-43.

34 Cf. SCHMIDT-BURKHARDT, Astrit (2004), op. cit., pp. 9-10 y 114-125. 
Y a modo de cierre, otra vuelta de tuerca: hacia el final de su vida George Maciunas, que gozaba de una considerable formación en historia del arte ${ }^{35}$, vio rechazada su solicitud de una beca en esta disciplina a la John Simon Guggenheim Memorial Foundation para la realización de un diagrama sobre la historia de la vanguardia. Curiosamente, la misma propuesta sí le fue aceptada por The National Endowment for the Arts ${ }^{36}$. De tal suerte que este trabajo y, por extensión, el de toda una vida consagrada al intento de orquestar -en Fluxus- futuro, presente y pasado, quedaba reconocido como proyecto artístico.

Volviendo a Zaj y a los tres ejemplos antes presentados de sus invitaciones y programas, es fácil observar que la relación establecida por el grupo con las huellas de su propio devenir fue marcadamente diferente a la de Maciunas o Vostell: la convocatoria a un suceso ya transcurrido (Traslado), el aviso sobre la desordenación que se aplicará a los datos consignados (Concierto Zaj por calles y plazas de Madrid), o la fijación a posteriori de un programa resultado de la aleatoriedad previamente anunciada (Viaje a Almorox), implican una subversión lúdica y sutilmente radical de la función comúnmente atribuida a las fuentes informativas. Esta alteración, que está casi siempre a la vista ${ }^{37}$, opera desde el propio soporte y formato subvertido, confiriendo a estos documentos una autorreferencialidad donde el gesto de informar queda conceptualizado y convertido en un evento en sí mismo.

Tanto es así, que estos papeles se suman y confunden con los demás cartones con los que Zaj dio lugar a uno de los capítulos más interesantes de la nueva práctica internacional del arte postal. La imbricación entre lo informativo y lo creativo latente en las tarjetas ya comentadas se intensifica, por ejemplo, mediante la depuración de una pieza como Encuentre a Zaj en el desierto (1967) de Juan Hidalgo (fig. 5). Aquí puede apreciarse de un solo vistazo una drástica reducción en el registro de datos, así como una enfatización del elemento sensorial, a saber, la visualidad del texto. Pero además, si se considera el escrito con algo más de detenimiento, puede sorprender el hecho de que el artista aproveche la constatación de nuestro desencuentro con él en Argelia para enviarnos sus saludos, lo que equivale a un cierto modo de encuentro. Así, este recordatorio de nuestra ausencia del lugar en el que realizó su acción para nosotros y donde, en todo caso, él ya tampoco está, se convierte en una forma de presencia ${ }^{38}$.

35 Basada en sus estudios en el Institute of Fine Arts de la New York University entre 1955 y 1960. Cf. Ibidem, p. 9.

36 Cf. Ibidem y MOORE, Barbara (1982), op. cit., pp. 41 y 45, n. 13.

37 Sólo una trampa se esconde en la lista de los colaboradores del Concierto por calles y plazas, donde se incluyen los nombres de dos personajes inventados. Para sus biografías ficticias, vid. SARMIENTO, José Antonio, "El recorrido Zaj”, en SARMIENTO, José Antonio (ed.) (1996), op. cit., p. 24, nota 8.

38 Sobre el nuevo tipo de presencia propuesto por la aparente ausencia de Zaj y, en general, como lectura que cimienta las reflexiones desarrolladas a continuación en este apartado, vid. CHARLES, Daniel, "Zaj, o 1'esplendor del buit", en Quaderns Fundació Caixa de Pensions, n 39, 1988, pp. 45-53. 


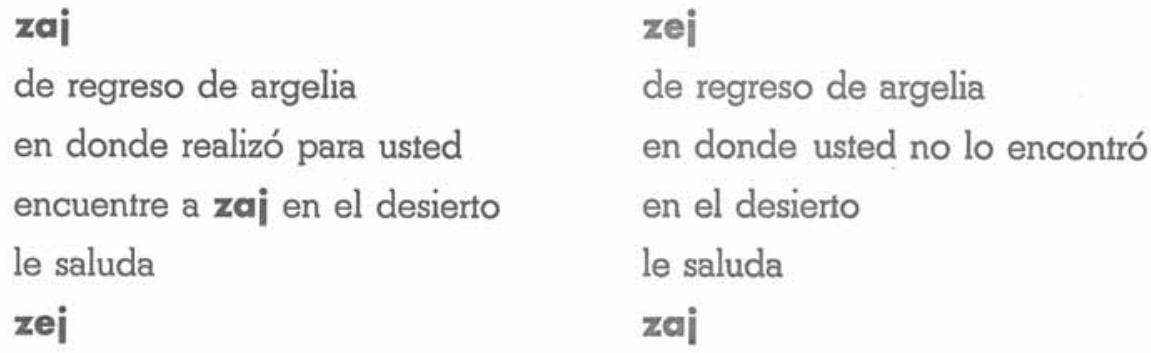

Fig. 5. Juan Hidalgo, Encuentre a Zaj en el desierto, 1967, impresión sobre cartón, 12 x 15 cm., anverso y reverso, Archivo Henar Rivière.

El programa del Viaje a Almorox (disecada excreción de todo lo que pudo ocurrir), o el del Concierto por calles y plazas (organizada llamada al azar), subrayan en realidad aquello que quedó fuera de ellos mismos como documentos, desplazando la atención desde los eventos concretos que comunican hacia el simple hecho de que las cosas sucedan, en todo lugar y momento, con o sin el testigo del público o de un registro documental. Y tan imposible fue para los contactos del grupo en 1964 asistir al Traslado, o en 1967 acudir a la acción de Hidalgo en Argelia, como lo es para nosotros en 2011, por lo que sus correspondientes invitaciones o anuncios de ausencias funcionan, paradójicamente, como "signos de existencia" o "de vida", según las palabras del escritor experimental vinculado a Zaj José Luis Castillejo (n. 1930). Unos signos que, usando la terminología del mismo autor, son infinitamente "actualizables". En ellos se plantea en efecto un nuevo tipo de temporalidad que, abandonando la tradicional concepción occidental del tiempo como una coordenada preexistente según la que ir ordenando los acontecimientos, lo concibe como algo "materializado, incorporado a las cosas" y que nace de la "relación entre los sucesos" ${ }^{39}$. Encuentre a Zaj en el desierto ofrece una buena muestra de ello al condensar los distintos momentos de varios aconteceres: (1) el envío de un saludo de Hidalgo, (2) su regreso de Argelia, (3) su realización de un evento para nosotros - aunque más correcto sería decir "para mi" como receptor privado de la postal, (4) mi gesto de darle la vuelta al cartón para terminar de leerlo, y descubrir (tal vez ya en el momento (5) que la acción que me ofreció el artista no es en realidad otra que la de estar yo en el salón de mi casa (por poner un ejemplo) descubriéndome a mí mismo en la lectura de este cartoncillo imposible $(\infty)$.

39 CASTILLEJO, José Luis, "La sensibilidad de lo actual", en CASTILLEJO, José Luis, Actualidad y participación. Una filosofia contemporánea, Madrid, Tecnos, 1968, pp. 13-14, 17-18 y 55. 
Análogamente, otros trabajos de Zaj proponen a su receptor una práctica privada que le reubique en los espacios y tiempos reales de su propia experiencia, liberándola así de las concepciones abstractas del "Tiempo" o la "Historia" como valores fijos y absolutos, apartados del mundo en su forzado intento de "imponerle un sentido determinado, unívoco" ${ }^{40}$. Con el Concierto postal (1965), por ejemplo, una serie de partituras que constituyen verdaderas piezas de poesía visual, fonética y conceptual, llegaron por correo a los hogares de los contactos del grupo, brindándoles la posibilidad de interpretarlas privadamente ${ }^{41}$. Junto a ello, y dando el salto desde el arte por correspondencia al del libro, en Zaj se elaboraron compendios -de informaciones y otras composiciones- como el Arpocrate seduto sul loto (19651968) con el que Walter Marchetti creó un tratado musical: una tipología de fuente que, de nuevo, subvierte la función que le es propia para propiciar una vivencia actualizable por cada cual ${ }^{42}$.

De esta manera jugaba (juega) Zaj con el concepto de documento: sus tarjetas consignan coordenadas espacio-temporales con una autorreferencialidad irónica que logra implicar y activar los tiempos y espacios del receptor. Estos cartones funcionan por ello como generadores de simultaneidades (las cuales ocurren siempre que alguien los lea), y así, se convierten en portadores de eventos o performances, que permanecen en estado latente hasta que alguien interactúe con ellos ${ }^{43}$. Consciente de la distancia abierta entre el acontecimiento y su registro, Zaj la abisma al señalarla, y la activa al abismarla, convirtiendo con ello el documento en acción: en un arte no separado de la vida que, aún dejándose archivar, logra poner sobre la cuerda floja la linealidad del concepto al uso de "Historia".

Y a modo de cierre, otra vuelta de tuerca que termina de situarnos de lleno en la confluencia entre el documento y la práctica artística: la más característica aportación de Zaj al arte de acción es el Etcétera, definido por Hidalgo como un "documento público" o kôan que busca precipitar la iluminación en el receptor ${ }^{44}$.

40 Ibidem, p. 12.

41 Cf. ZAJ, Festival Zaj 1 - Concierto postal, nov.-dic. de 1965.

${ }^{42}$ Cf. RIVIÈRE, Henar, "Arpocrate seduto sul loto", en DÍAZ-BERTRANA, Carlos (ed.), Walter Marchetti. Música visible, Las Palmas de Gran Canaria, CAAM, 2004, pp. 19-31; para una versión reducida e ilustrada vid. http://elaguilaediciones.wordpress.com/2009/10/05/arpocrate-seduto-sul-loto-de-walter-marchetti-por-henar-riviere/ (fecha de última consulta: 07.06.2011).

43 Los cartones Zaj constan del elemento "interpretativo" (en el sentido literal del término inglés performance o, equivalentemente, del alemán Aufführung), siendo el propio receptor su intérprete; además, comparten los rasgos esenciales del concepto de lo "performativo" según los formulara por primera vez John L. Austin en 1955 desde el ámbito de la lingüística: autorreferencialidad y capacidad transformadora de la realidad (o, añadiríamos, de la percepción de la misma). Cf. AUSTIN, John. L., How to do things with words, Oxford \& New York, Oxford University Press, 1988 (1962), pp. 1-11.

${ }^{4}$ Cf. HIDALGO, Juan, "Zaj”, en Revista de Letras, t. I, no 3, 1969, p. 431, y en HIDALGO, Juan y GAVIÑO DE FRANCHY, Carlos (eds.), Zaj, Madrid, Consejería de Cultura y Deportes, Gobierno de Canarias, 1987, s./p. Vid. también PÉREZ, David, "El arte sin géneros: los etcéteras y el Viaje a Argel" (1993), en PÉREZ, David (2008), op. cit., p. 40. 
Y sospecho que precisamente lo que ese signo lingüístico (“etc.”) omite de aquello que quedaba por decir en una imaginaria frase ${ }^{45}$, esto es, que precisamente el anuncio de la ausencia implícita en él, es lo que desencadena en el receptor el libre hacer de la conciencia, y una vivencia renovada de su ser en el tiempo y el espacio.

\section{Conclusión: ahondar distancias}

Actuando al margen de los circuitos oficiales del arte, tanto Fluxus como Zaj tuvieron que (o quisieron) dedicar una parte muy importante de su propia actividad a la emisión de documentos que anunciaran o recordaran, que construyeran e imaginaran su efímero quehacer. Jueces y parte a un mismo tiempo, elaboraron así un legado en el que los registros de información se amalgaman con sus inquietudes artísticas y vitales (de índole más filosófica en el caso de Zaj, y social en el de Maciunas). De tal manera, las inertes presentaciones de datos se vivifican convirtiéndose en reflejos o ejemplos de estas búsquedas y, viceversa, éstas se realizan, en diferentes grados y con distintos matices, bajo la forma de documentos. Tal voluntad de realización -de intervención en la realidad, o en lo que, quizás más precisamente, Jaques Rancière denomina "el reparto de lo sensible" 46 - emerge de este legado especialmente como un intento deliberado de reconfigurar los modos de hacer (Maciunas) y de concebir (Zaj) la "historia": en su diálogo con ella, Zaj y Fluxus buscaron una alteración de sus términos. Debe concluirse, por tanto, que el desafío planteado por el arte de acción a la historiografía del arte no es una consecuencia casual, sino un elemento consustancial a su práctica, al menos en lo referente al grupo español y al promotor de la red internacional de artistas. De un modo lúdico y gamberro el primero, concienzudo y quijotesco el segundo, ambos se dejan sentir y conocer con singular intensidad precisamente en la brecha abierta entre lo sucedido y su huella, y laten presentes en sus propias pequeñas imposibilidades, a saber, las marcas de ausencias Zaj y el maciunesco desajuste entre "realidad" e "ilusión".

45 Es Pérez quien pone el acento sobre el origen lingüístico del término "etcétera”, cf. PÉREZ, David, "Entre paréntesis" (2007), en Ibidem, p. 118.

46 RANCIÈRE, Jaques, El reparto e lo sensible, Santiago de Chile, LOM Ediciones, 2009, pp. 9-19. 